\title{
Freshwater diatom persistence on clothing II: Further analysis of species assemblage dynamics over investigative timescales
}

\author{
K.R. Scott ${ }^{\mathrm{a}, \mathrm{b}, \mathrm{c}, *}$, V.J. Jones ${ }^{\mathrm{d}}$, N.G. Cameron ${ }^{\mathrm{d}}$, J.M. Young ${ }^{\mathrm{e}}$, R.M. Morgan ${ }^{\mathrm{b}, \mathrm{c}}$ \\ ${ }^{a}$ School of Biological E' Environmental Sciences, Liverpool John Moores University, Byrom Street, Liverpool L3 3AF, United Kingdom \\ ${ }^{\mathrm{b}}$ Department of Security \& Crime Science, University College London, 35 Tavistock Square, London WC1H 9EZ, United Kingdom \\ ${ }^{\mathrm{c}}$ Centre for the Forensic Sciences, University College London, 35 Tavistock Square, London WC1H 9EZ, United Kingdom \\ ${ }^{\mathrm{d}}$ Environmental Change Research Centre, University College London, Department of Geography, North West Wing, Gower Street, London WC1E 6BT, United \\ Kingdom \\ ${ }^{\mathrm{e}}$ College of Science \& Engineering, Flinders University, Adelaide, Australia
}

\section{A R T I C L E I N F O}

\section{Article history:}

Received 2 December 2020

Received in revised form 23 June 2021

Accepted 29 June 2021

Available online 4 July 2021

\section{Keywords:}

Environmental trace evidence

Diatom analysis

Persistence

Clothing

Species dynamics

Forensic ecology

\begin{abstract}
A B S T R A C T
Diatoms are a useful form of environmental trace evidence, yielding a circumstantial link between persons and scenes of forensic interest. A developing empirical research base has sought to understand those factors affecting the transfer and persistence of freshwater diatoms on clothing and footwear surfaces. Although an initial study has demonstrated that diatoms can persist on clothing following weeks of wear, no previous research has explored the temporal dynamics of a persistent species assemblage over timescales pertinent to forensic investigations. This study therefore aimed to determine if: (1) valve morphology (size and shape) influences diatom persistence, (2) the relative abundance of taxa within an assemblage affects retention, and (3) a persistent diatom assemblage retrieved from clothing after one month can reliably be compared to the site of initial transfer. To build on previous research findings which highlighted the impact of substrate and environmental seasonality on diatom transfer and persistence, here, nine clothing materials were tested in spring before a seasonal comparison in the winter. Fabric swatches were immersed in a freshwater river, worn attached to clothing, and subsamples retrieved at regular intervals (hours, days, weeks) up to one month post-immersion. Diatoms were extracted using a $\mathrm{H}_{2} \mathrm{O}_{2}$ technique and analysed via microscopy. The results indicated that smaller diatoms $(<10 \mu \mathrm{m})$ are retained in significantly greater abundance, with no statistically significant difference between centric and pennate diatom loss over time. Although a persistent species assemblage was relatively stable over the one month of wear, significant differences were identified between clothing substrate in the spring and between the seasonal samples. The most abundant environmental taxa were consistently identified in the forensic samples, with greater variability attributed to the retention of relatively less common species. The findings suggest that, despite a loss in the abundance and species-richness of diatoms retrieved from clothing over time, a persistent assemblage may provide a useful circumstantial link to the site of initial transfer. The complex relationships between clothing type, environmental seasonality, and time since wear on retention, emphasise the need for diatom trace evidence to be carefully interpreted within an exclusionary framework, and the significance of any casework findings to be determined with reference to empirical evidence bases.
\end{abstract}

(c) 2021 The Author(s). Published by Elsevier B.V.

\section{Introduction}

To ascertain the importance of trace evidence within forensic reconstructions, it is imperative to consider the spatial and temporal dynamics of that evidence prior to its collection. This is especially

* Corresponding author at: School of Biological \& Environmental Sciences, Liverpool John Moores University, Byrom Street, Liverpool L3 3AF, United Kingdom. E-mail address: k.r.scott@ljmu.ac.uk (K.R. Scott). important in the case of environmental trace indicators, including pollen and diatoms, which are known to vary in number and in type based on seasonal variations [1]. Empirical research has focused on factors impacting the transfer and persistence dynamics of physical (e.g. fibre, glass, gunshot residues [2-4]) and environmental (e.g. soil, pollen, diatom [5-7]) forms of forensic evidence. The data and inferences gained through such testing are frequently incorporated within analysis and exclusionary interpretation frameworks in forensic casework [8]. 
Previous persistence studies, including those of environmental trace indicators, typically focus only on quantitative trends, including absolute counts or relative retention (\%) over time [7,9]. However, the species richness, diversity, and variability of bioenvironmental trace evidence affords additional forensic value when recognised [10]. The assemblage of microorganisms including pollen, diatoms, and bacterial communities within a site, and subsequently transferred as evidence, is often vastly different even over discrete timescales and distances [11]. Such diversity adds value to forensic comparisons and exclusions, although the stability of an assemblage post-transfer, and its ability to reliably indicate the source of initial contact, must be considered during evidence interpretation [6]. Empirical research pertaining to the persistence dynamics of an environmental species assemblage recovered from evidential items, is therefore necessary to provide a secondary level of intelligence for forensic reconstructions.

Diatoms are a species-rich group of unicellular algae (Bacillariophyceae), frequently used as indicators of drowning in forensic pathology [12], and as a form of environmental trace evidence [13]. There are over 12,000 known species, all characterised by a resistant silica cell wall and species-specific valve features and ornamentation [14]. Previous forensic studies have demonstrated that diatom transfer is affected by immersion time, clothing substrate, seasonality, and valve/species characteristics (e.g. shape) $[13,15]$. Additional persistence research indicates diatom retention on footwear [16] and clothing [7] following weeks of wear, although the species dynamics of a persistent assemblage have not yet been explored. Given the species-richness (> 50 species [15]) and seasonal diversity of a transferred forensic sample, it is imperative to assess the stability of this assemblage over investigative timescales (hours to days and weeks). Such qualitative assessment would extend initial diatom persistence findings and contribute meaningful intelligence to inform forensic interpretations based on sample comparison and exclusions over time [17].

Temporal species dynamics have previously been incorporated within forensic palynology persistence research. Studies have shown that palynomorph size [9], shape, structure, surface pattern, and pollination mechanism [6] all impact the loss of pollen from clothing when worn post-transfer. Such variability recommends caution when inferring overall persistence trends during environmental evidence interpretation. The increased loss of material based on species morphology and ornamentation suggests that a recovered assemblage may not always contain a representative number, or species-richness, of pollen as an initial transfer sample which may limit forensic comparison and exclusions with a questioned environment(s) [18]. The findings from these studies emphasise the need for similar empirical approaches within other areas of forensic ecology, including diatom trace evidence analysis.

This paper aims to develop and extend the forensic understanding of diatom persistence on clothing following wear over investigative timescales ranging from hours to weeks. Building on initial diatom transfer [15] and overall persistence research [7], this study initially assesses the impact of diatom shape (centric [round], pennate [elongate]) and diatom size $(<10 \mu \mathrm{m},>10 \mu \mathrm{m})$ on retention (\%) following $30 \mathrm{~min}, 1 \mathrm{~h}, 2 \mathrm{~h}, 4$ h, 8 h, 16 h, 24 h, 48 h, 168 h (one week), $336 \mathrm{~h}$, and $720 \mathrm{~h}$ (one month) of wear. Additional analyses of species dynamics sought to determine if abundant and less common taxa are persistent on clothing, and whether a retained species assemblage can reliably be compared to an environmental sample from the site of initial transfer over time. Nine common clothing garments were tested in the spring and in the winter to determine if species persistence trends were consistent when fewer diatoms are known to transfer [15], and when environmental diatom communities are less abundant and species-rich [19]. Finally, this study sought to be as forensically pertinent as possible and was designed to replicate the circumstances which may be encountered in casework including the regular sustained wear of clothing before its recovery as forensic evidence.

\section{Methods}

Full details of the sampling approach and laboratory protocol can be found in [7]. Briefly, diatom persistence was tested up to one month $(720 \mathrm{~h})$ of wear following transfer to nine common clothing items with different surface textures and woven structures - cotton, nylon, polyester, linen, lycra, viscose, acrylic, PVC, and denim. To reflect seasonal trends in diatom transfer [15] and overall persistence [7], analyses of species retention dynamics over time were conducted at two different times of year. Initially, all nine clothing materials were tested in the spring (March-April 2015), before a seasonal comparison of cotton, acrylic, and nylon in the winter (November-December 2015). These were chosen to reflect the three distinct trends in overall diatom persistence reported in spring [7].

Swatches of each clothing material were removed from the whole garment, attached to a pair of waterproof trousers, immersed, and walked through a $5 \mathrm{~m}$ transect of the River Beane (Hertfordshire, UK) (National Grid Ref: TL313148). Diatom transfer was initiated for 3 min [13]. To provide a reference of the diatom species present at the scene, a $500 \mathrm{ml}$ sample of water and any suspended material was collected from the same transect. Immediately post-transfer, the clothing swatches were reattached to a coat and worn for a total of one month (30 days). Sub-samples $\left(1 \mathrm{~cm}^{2}\right)$ were retrieved at regular intervals of wear: $0.5,1,2,4,8,16,24,28,168,336,720$ h. Following removal, the subsamples were double bagged and stored $\left(5^{\circ} \mathrm{C}\right)$. Three replicates of each clothing and environmental sample were used throughout.

Diatoms were extracted from all subsamples using the $\mathrm{H}_{2} \mathrm{O}_{2}$ method outlined in $[13,15]$. Microscope slides were created using $500 \mu \mathrm{l}$ of the final sample aliquot transferred to a $19 \mathrm{~mm}$ round coverslip using a calibrated micropipette. Naphrax ${ }^{\mathrm{TM}}$ was used to permanently fix the samples for analysis. Blank samples $(n=45)$ were prepared throughout to check for any potential contamination during laboratory preparation.

The samples $(n=477)$ were examined at x1000 magnification using phase-contrast light microscopy. All diatoms from a known area of the coverslip were counted, recorded, identified to specieslevel, and the morphological features noted (size, shape) (Fig. 1) $[15,20]$. The dynamics of a persistent forensic assemblage were assessed via comparison of diatom retention (\%) by morphology, temporal species composition changes, and the efficacy of a recovered assemblage to indicate the site of initial transfer over time. Statistical analysis was performed using SPSS (v. 25), PRIMER-E, and $\mathrm{C} 2$.

\section{Results}

Overall diatom persistence trends, including the estimated total number of diatoms per sample and retention (\%) over time are presented in [7]. No diatoms were present in the blank samples.

\subsection{Impact of diatom morphology on retention}

\subsubsection{Valve shape}

Diatom retention was initially compared based on valve shape centric (round), raphid and araphid pennate (elongate) (Fig. 1). A three-way ANOVA examined the interaction between clothing type, shape, and time since wear on diatom retention (\%) in the spring. There was no statistically significant interaction between the three variables $-F(64,891)=0.390, p=1-$ or between each pairwise comparison $(p>.05)$. There was no significant difference in retention between the three diatom shapes $(p=.195)$, the nine clothing materials $(p=.179)$, and the persistence intervals $(p=.814)$. 

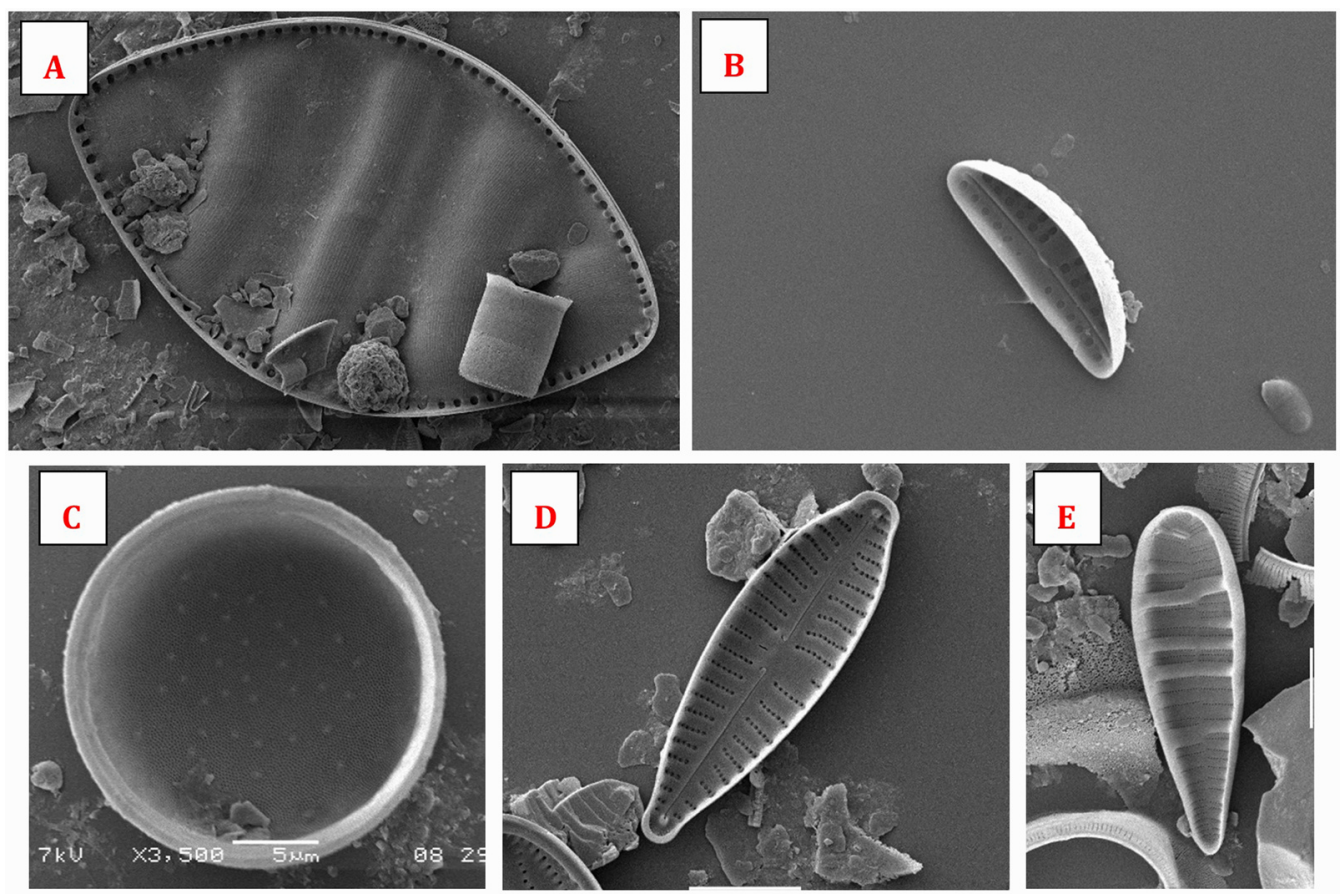

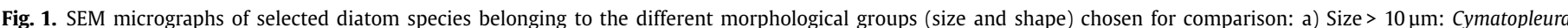

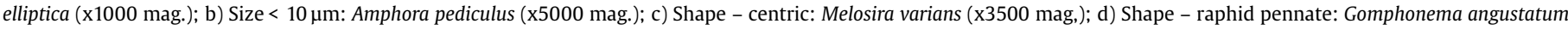
(x4500mag.); e) Shape - araphid pennate: Meridion circulare (x4300mag.). All images were taken using Jeol JSM-6480LV.

Although the \% retention of the three diatom groups was not significantly different, some diversity was reported in the decay curve for each clothing substrate (Supplementary Fig. 1). For example, the loss of centric and pennate diatoms from cotton, linen, denim, and acrylic was relatively consistent over time, with more complex retention patterns in polyester, PVC, lycra (driven by araphid pennates), nylon (araphid, centric diatoms), and viscose (both pennate groups). After one month, raphid pennate taxa were retained in greater abundance than centric and araphid pennates, which were often missing from some of the latter interval samples (Supplementary Fig. 1a, d, e, h).

Cotton, nylon, and acrylic were chosen for a seasonal comparison of diatom persistence as the three reported different trends in the spring [7]. A four-way ANOVA found no significant interaction between season, persistence interval, clothing type, and valve shape on diatom retention $(\%)-F(16,594)=.671, p=.823$ - or between any two- or three-way comparisons $(p>.05)$. Although centric and pennate valve retention was not significantly different between spring and winter $(p=.368)$ or persistence interval $(p=.577)$, diatom loss from cotton and acrylic was significantly greater than from nylon $(p<.0001)$. As in the spring, the loss of diatoms based on shape was most variable over time in nylon, although all three diatom groups reported similar temporal fluctuations (Supplementary Fig. 2b). In comparison, there was greater variability between the different diatom morphologies persistent on acrylic and cotton. For example, although the loss of centric diatoms from acrylic was consistent over time (100-8\%), both pennate groups reported complex persistence trends. Similar inconsistencies were identified in the retention of raphid pennate and centric diatoms on cotton clothing (Supplementary Fig. 2).

\subsubsection{Valve size}

The persistence of diatoms in two size fractions ( $<$ and $>10 \mu \mathrm{m}$ ) was also explored (Fig. 2). A three-way ANOVA demonstrated no statistically significant interaction between clothing type, persistence interval, and diatom size on retention (\%) in the spring $-F(32$, $594)=0.224, p=1-$ and no significant pairwise interactions between any of the variables $(p<.05)$. A significant difference between clothing type was identified $(p<.0001)$ due to diatom persistence dynamics on lycra compared to all other materials, and viscose compared to cotton and polyester $(p<.05)$. Significantly fewer diatoms were retained beyond $8 \mathrm{~h}$ of wear $(p<.0001)$ and smaller diatoms $(<10 \mu \mathrm{m})$ were retained in significantly greater abundance than larger valves across the nine materials tested $(p=.043)$.

Cotton was the only sample substrate where $>10 \mu \mathrm{m}$ diatoms were retained in greater quantities throughout (Fig. 2a). The temporal loss of both size fractions was relatively consistent in linen, polyester, and acrylic. In comparison, the retention of smaller diatoms in viscose, nylon, lycra, and PVC demonstrated variability in at least one of the earlier (1-4h) interval samples (Fig. 2e, g, h, i). Importantly, diatoms from both size fractions were retained in the $720 \mathrm{~h}$ forensic assemblage although smaller diatoms were more abundant than larger taxa.

The winter comparison of diatom persistence on cotton, nylon, and acrylic demonstrated greater variability between larger and smaller valve retention (Fig. 3). A four-way ANOVA identified a significant interaction between diatom size, season, persistence interval, and clothing type on retention $-F(8,336)=2.782, p=.005$. All three-way interactions were significant as were the two-way interactions between season and: clothing type, diatom size; clothing and: persistence group; size and: persistence group $(p<.05)$. Diatom retention was significantly greater in winter $(p=.001)$ and amongst smaller diatoms $(p=.012)$. Although fewer diatom species were retained on cotton in the winter (Supplementary Table 1b), the decay dynamics of both size fractions were comparable to the spring (Fig. 3). Seasonal persistence trends were less consistent in acrylic, although the greatest variability was reported in nylon where smaller diatoms were often missing from a retained assemblage.

\subsection{Temporal species assemblage dynamics}

Full information on all persistence samples species composition is included as supplementary information [Supplementary Data]. More diatom species were identified in the spring persistence 

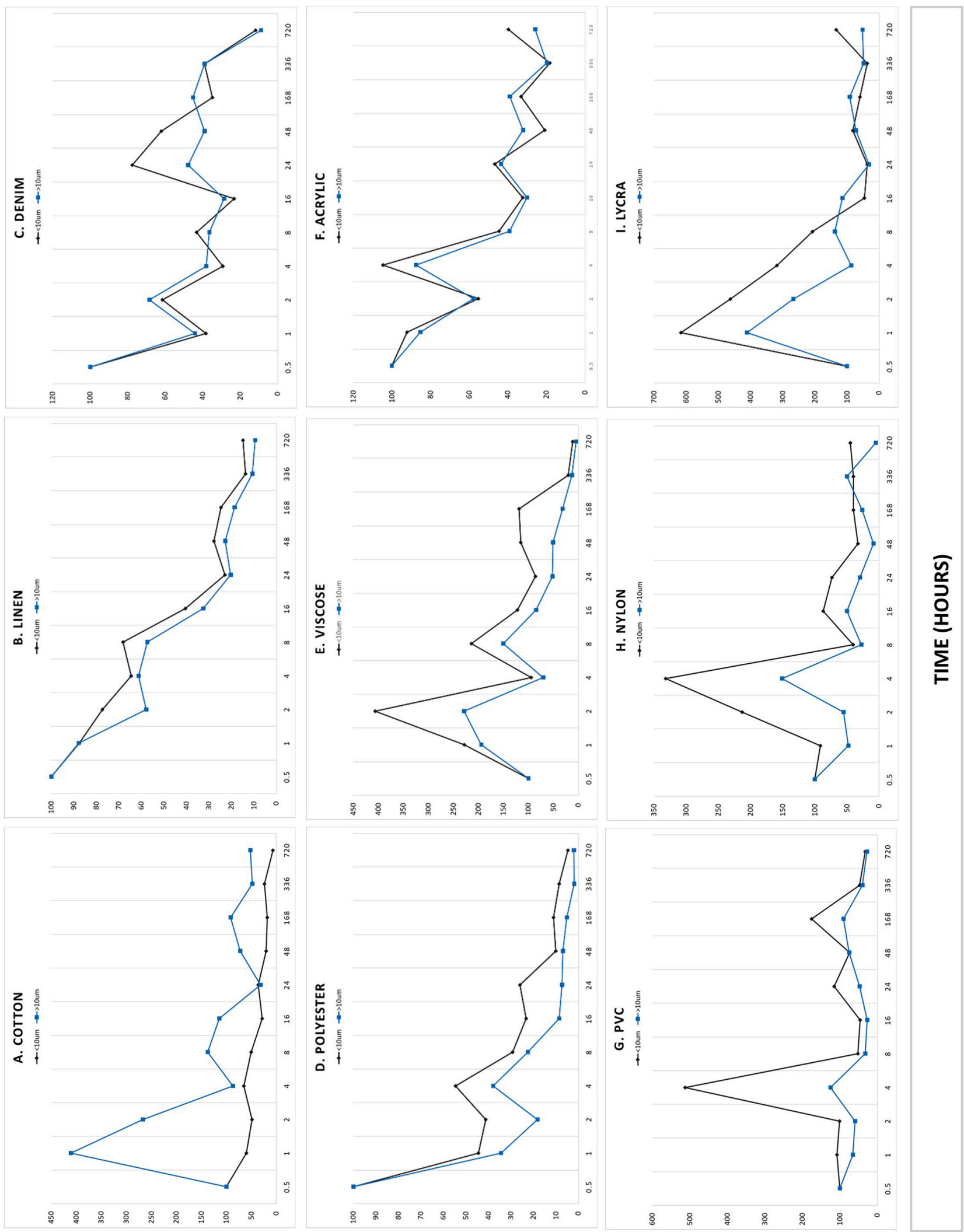

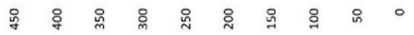
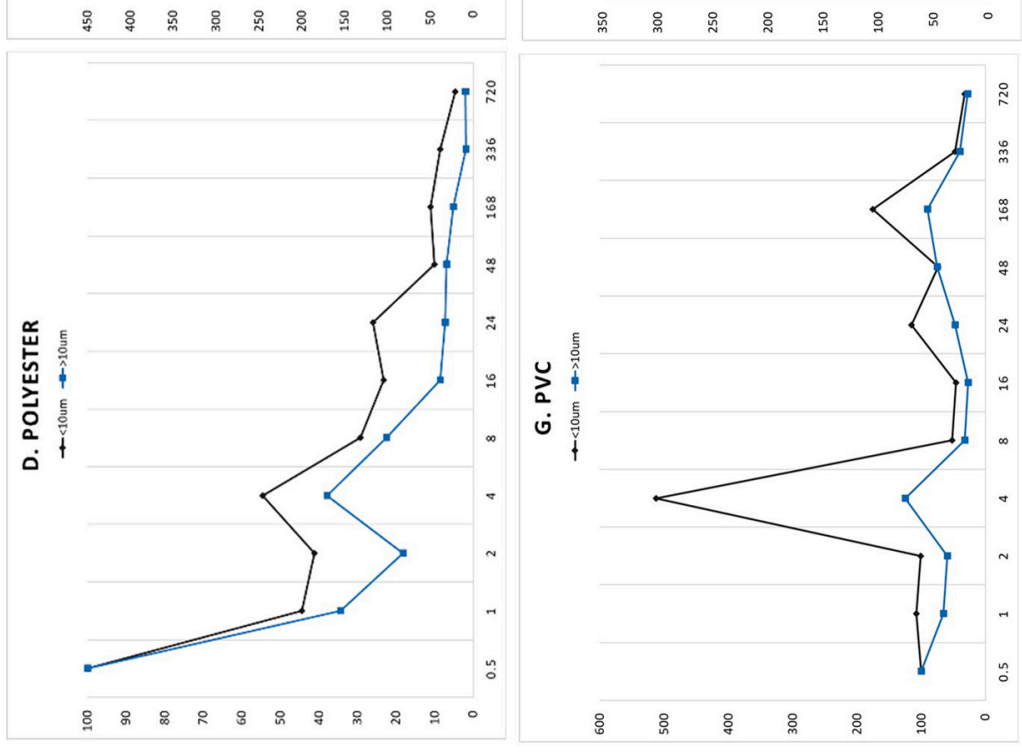

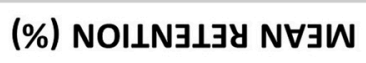

Fig. 2. a-i: The mean retention (\%) of diatoms less than (<) and greater than ( $>) 10 \mu \mathrm{m}$ in size on the nine clothing materials tested following up to one month $(720 \mathrm{~h})$ of wear in the spring $(n=3)$. 


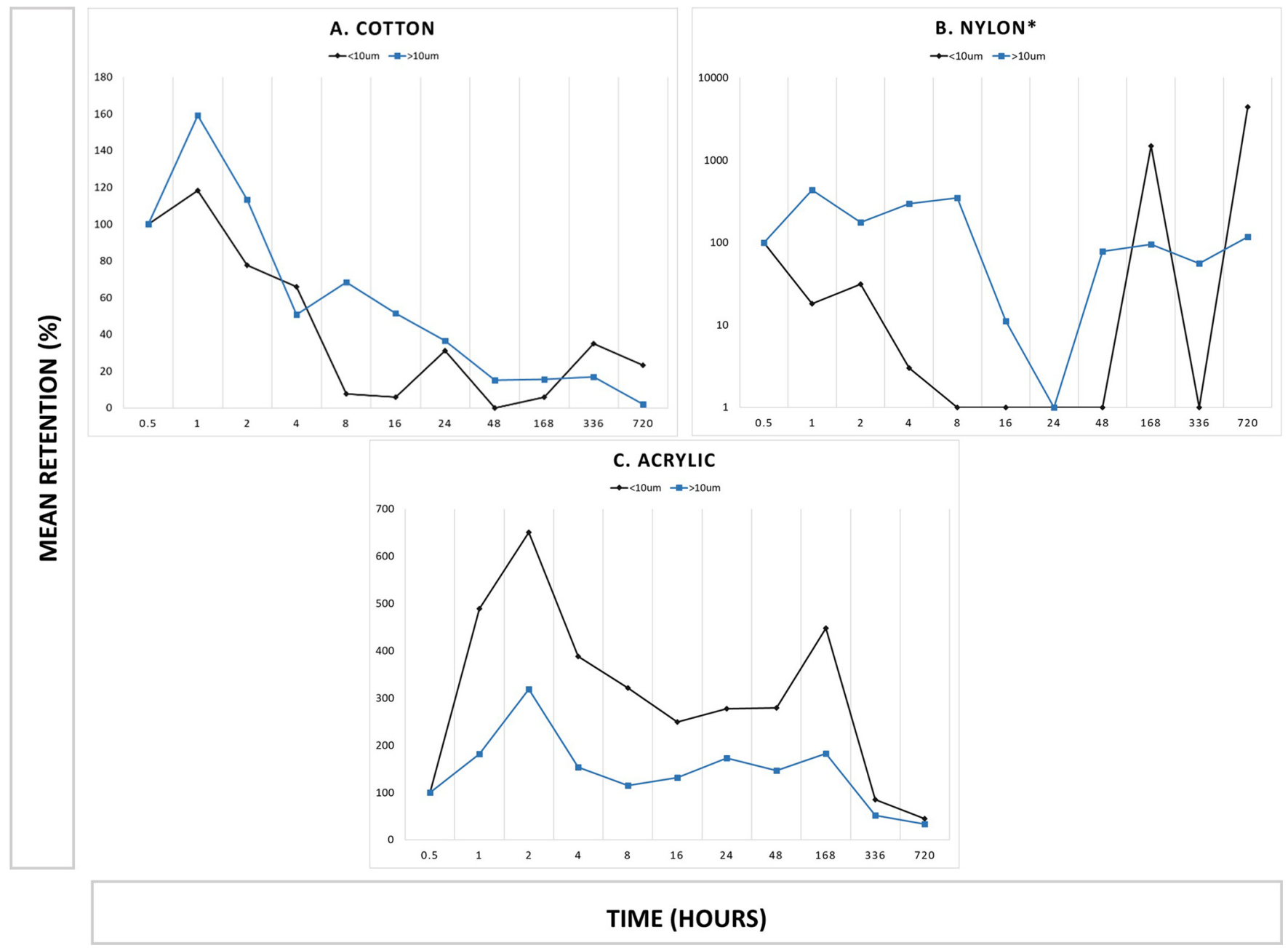

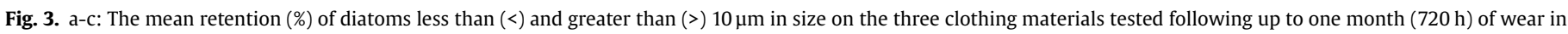
the winter $(n=3)$.

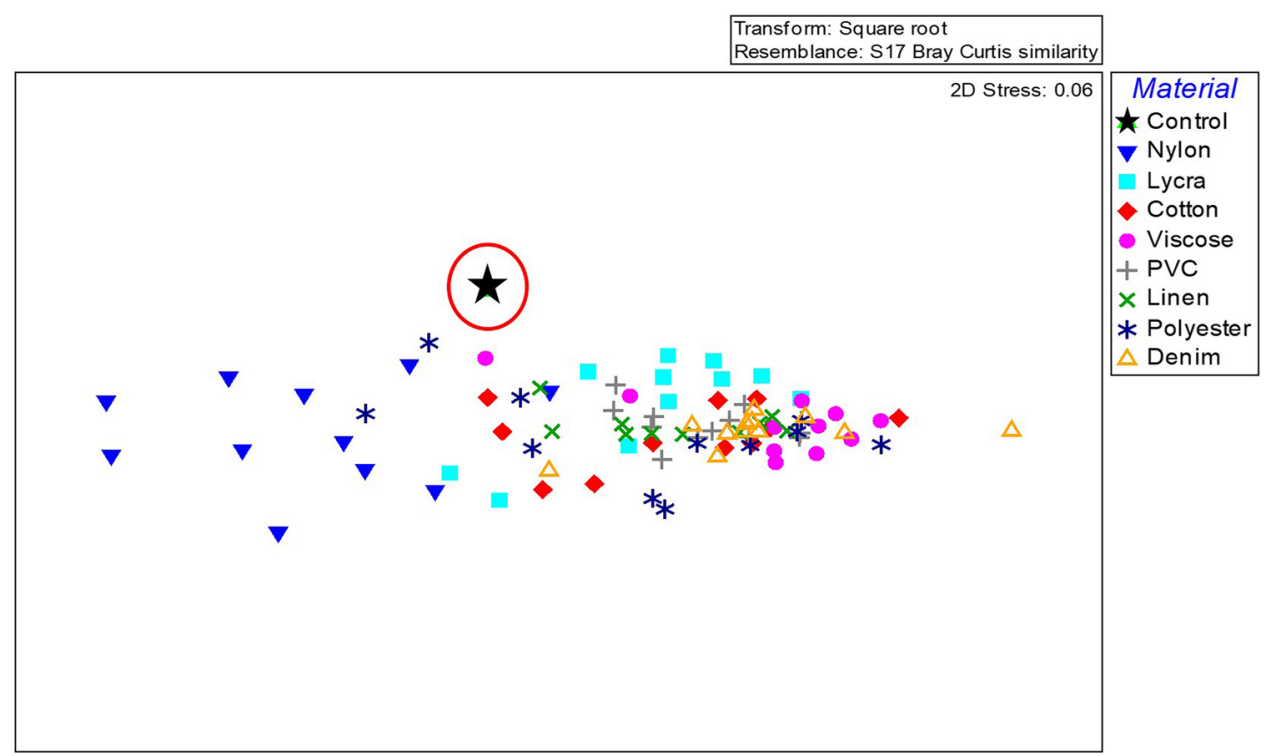

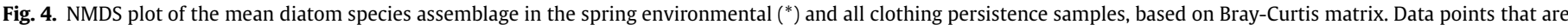

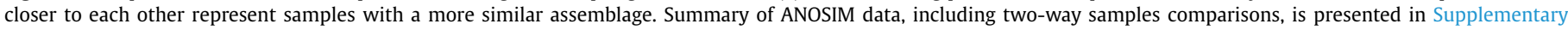
Table 2 and Supplementary Fig. 3. 
samples $(\bar{x}: 5-71 \mathrm{sp}$.$) than in winter (\bar{x}: 3-32 \mathrm{sp}$.) (Supplementary Table 1). Fewer taxa were retained in the later persistence intervals, with a more rapid loss of species-richness in the winter (beyond $8 \mathrm{~h}$ ) than in the spring (beyond $48 \mathrm{~h}$ ). Variability in species retention between clothing type was reported, with nylon comprising fewer taxa in both seasons ( $\bar{x}: 14-6 \mathrm{sp}$. [spring], 5-3 sp. [winter]) compared to all other fabrics.

\subsubsection{Whole sample species composition}

The relative similarity of the species assemblage across all spring persistence samples was statistically compared via ANOSIM based on the Bray-Curtis similarity index (99\% CI). No significant difference was identified in the overall diatom assemblage between the eleven persistence intervals - global $R=0.131, p=.001$, although the later persistence samples (beyond $24 \mathrm{~h}$ ) were more variable than the assemblage retrieved following $0.5-8 \mathrm{~h}$ of wear (Supplementary Fig. 3). The species assemblage retained over time was significantly different when comparing persistence samples by clothing type global $R=0.254, p<.0001$ (Fig. 4). This variability was driven by nylon, which had a significantly different assemblage compared to all other materials ( $p<.0001)$ (Supplementary Table 2 ).

Forty-nine diatom species were identified in the environmental sample assemblage retrieved at the transfer site in the spring. Of these taxa, fewer than 30 were typically retrieved from the clothing persistence samples over time, although 5-30 sp. were still present following $720 \mathrm{~h}$ of wear (Fig. 5a). Fewer environmental species were consistently identified in nylon (5-19 sp.) compared to all other clothing materials (20-41 sp.). Amphora pediculus, Navicula radiosa, and Rhoicosphenia curvata were the only taxa consistently observed in the mean sample species assemblage of all 11 nylon persistence intervals (Fig. 5b). The other eight clothing substrates consistently retained additional species including Achnanthes lanceolata, Melosira varians, and Cocconeis placentula. Acrylic was the most effective retention surface for the persistence of taxa including Cymbella sinuata, Nitzschia gracilis, and Fragilaria vaucheriae, which were less consistently identified in the other eight materials. Several species present in the environmental samples were entirely absent from all clothing persistence samples including Navicula placentula and Achnanthes laterostrata [Supplementary Data].

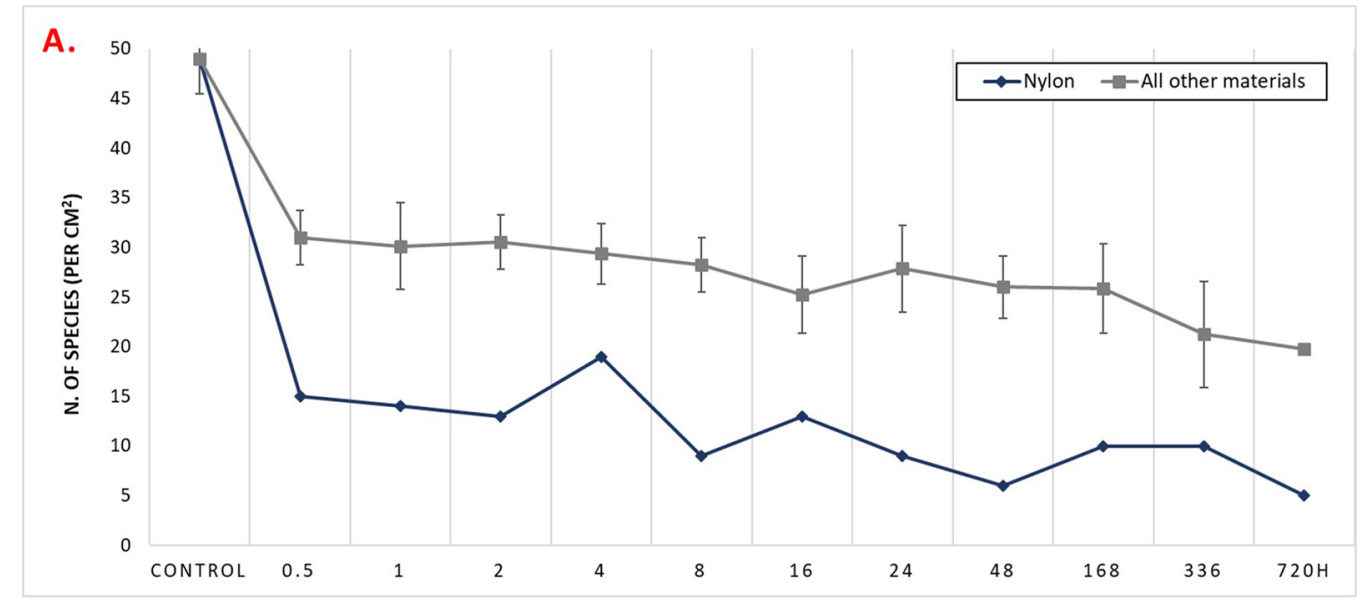

\begin{tabular}{|c|c|c|c|c|c|c|c|c|c|}
\hline B. & Cotton & Linen & Denim & Polyester & Viscose & Acrylic & PVC & Lycra & Nylon \\
\hline Amphora pediculus & $*$ & $*$ & $*$ & $*$ & $*$ & $*$ & $*$ & $*$ & $*$ \\
\hline Navicula radiosa & $*$ & $*$ & $*$ & $*$ & $*$ & $*$ & $*$ & $*$ & $*$ \\
\hline Rhoicosphenia curvata & $*$ & $*$ & $*$ & $*$ & $*$ & $*$ & $*$ & $*$ & $*$ \\
\hline Achnanthes lanceolata & $*$ & $*$ & $*$ & $*$ & $*$ & $*$ & $*$ & $*$ & - \\
\hline Melosira varians & $*$ & $*$ & $*$ & $*$ & $*$ & $*$ & $*$ & $*$ & - \\
\hline Nitzschia dissipata & $*$ & $*$ & $*$ & $*$ & $*$ & $*$ & $*$ & $*$ & - \\
\hline Achnanthidium minutissimum & $*$ & * & $*$ & $*$ & $*$ & $*$ & $*$ & - & - \\
\hline Cocconeis placentula & $*$ & $*$ & $*$ & - & $*$ & $*$ & $*$ & $*$ & - \\
\hline Surirella brebissonii & $*$ & $*$ & $*$ & $*$ & $*$ & $*$ & $*$ & - & - \\
\hline Cocconeis pediculus & - & $*$ & $*$ & - & $*$ & $*$ & $*$ & $*$ & - \\
\hline Nitzschia linearis & - & $*$ & $*$ & - & $*$ & $*$ & $*$ & $*$ & - \\
\hline Navicula gregaria & $*$ & * & - & - & - & $*$ & $*$ & - & - \\
\hline Navicula menisculus & - & $*$ & $*$ & - & $*$ & $*$ & - & - & - \\
\hline Amphora libyca & $*$ & - & - & - & - & $*$ & $*$ & - & - \\
\hline Navicula minima & - & - & $*$ & - & - & $*$ & $*$ & - & - \\
\hline Navicula tripunctata & - & - & - & - & $*$ & $*$ & - & - & - \\
\hline Cymbella sinuata & - & - & $*$ & - & - & - & - & - & - \\
\hline Fragilaria parasitica & - & - & - & - & - & $*$ & - & - & - \\
\hline Fragilaria vaucheriae & - & - & - & - & - & $*$ & - & - & - \\
\hline Navicula cryptocephala & - & - & - & - & - & $*$ & - & - & - \\
\hline Navicula pupula & - & $*$ & - & - & - & - & - & - & - \\
\hline Nitzschia gracilis & - & - & - & - & - & $*$ & - & - & - \\
\hline
\end{tabular}

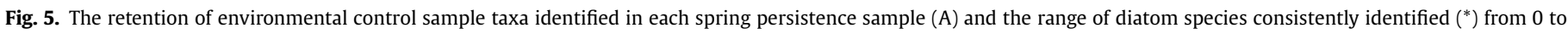

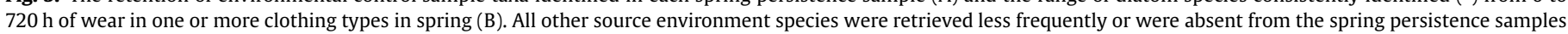
[Supplementary Datafile]. 


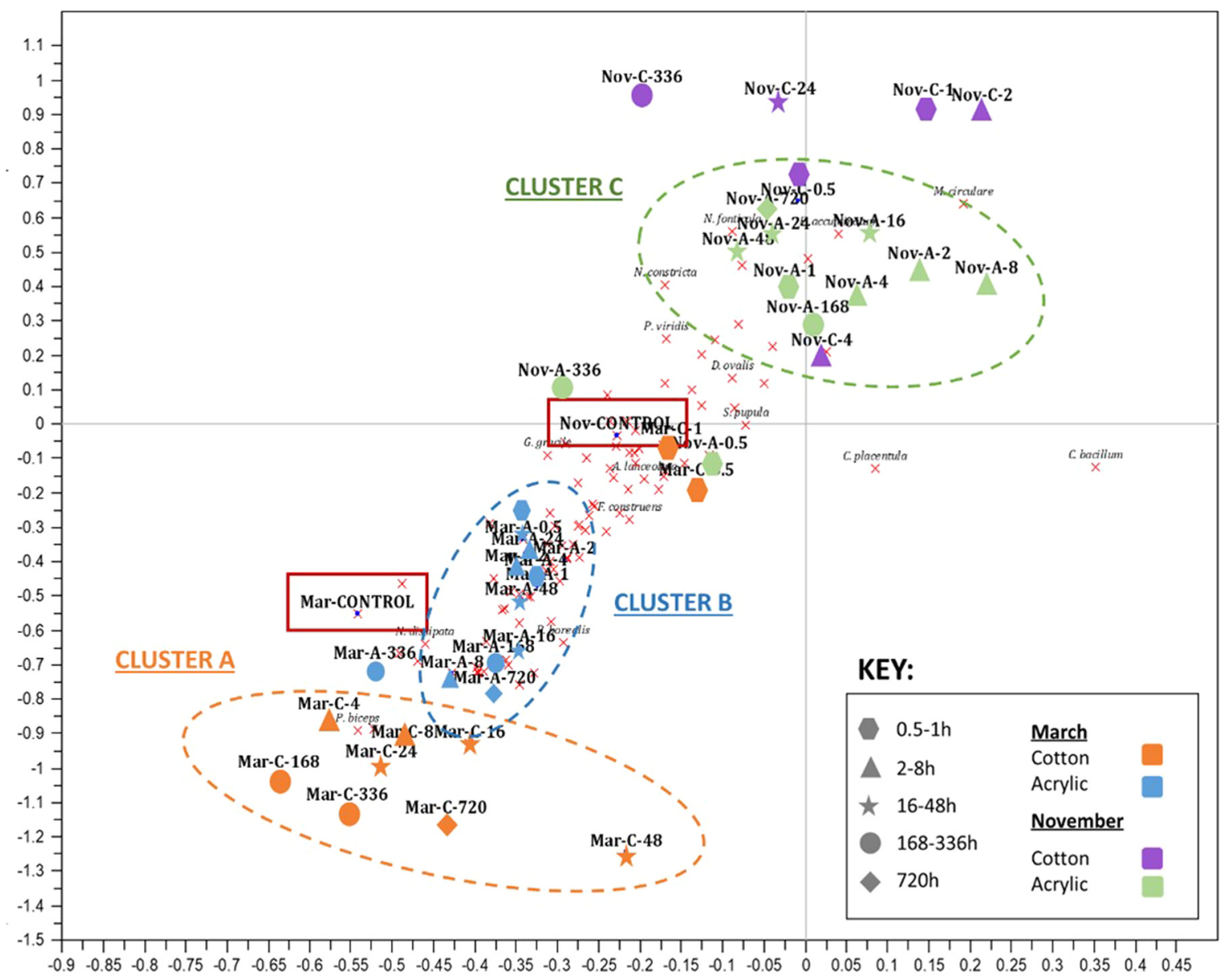

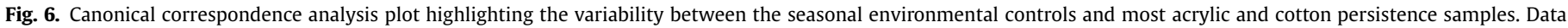

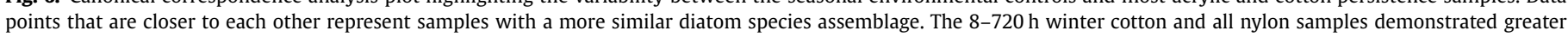
variability and are presented in Supplementary Figs. 4 and 5.

Although fewer diatom species were recovered from the winter persistence samples, the whole sample species assemblage of each was statistically compared to the spring counterpart and the corresponding environmental controls (Fig. 6, Supplementary Figs. 4, 5). The acrylic persistence samples species composition most closely resembled that of the environmental assemblage in both the spring (Fig. 6, cluster B) and winter (cluster C). More variability was purported amongst the cotton samples. Although eight of the spring persistence samples demonstrated relative similarity to the environmental control, all winter cotton samples were less representative of the transfer site (Fig. 6, Supplementary Fig. 4). The greatest variability from the winter environmental sample was observed beyond $8 \mathrm{~h}$ of wear due to the abundance of taxa including Gomphonema augur, Cyclotella planktonica, and Navicula tryblionella.

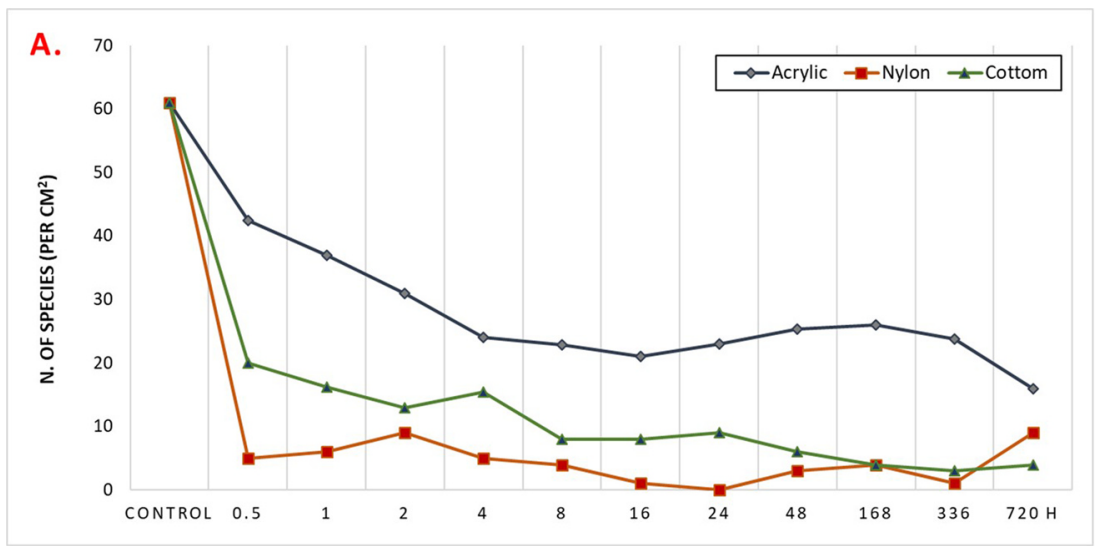

\begin{tabular}{|l|ccc|}
\hline \multicolumn{1}{|c|}{ B. } & Cotton & Acrylic & Nylon \\
\hline Melosira varians & $*$ & $*$ & - \\
Achnanthes lanceolata & - & $*$ & - \\
Amphora pediculus & - & $*$ & - \\
Cocconeis placentula & - & $*$ & - \\
Navicula cryptotenella & - & $*$ & - \\
Navicula tripunctata & - & $*$ & - \\
Nitzschia amphibia & - & $*$ & - \\
Nitzschia dissipata & - & $*$ & - \\
Rhoicosphenia curvata & - & $*$ & - \\
Surirella brebissonii & - & $*$ & - \\
\hline
\end{tabular}

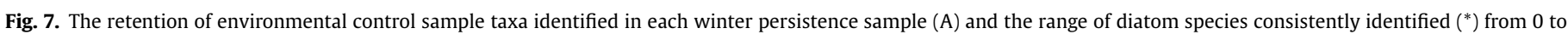

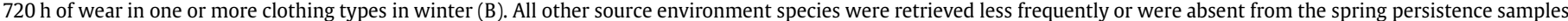
[Supplementary Datafile]. 


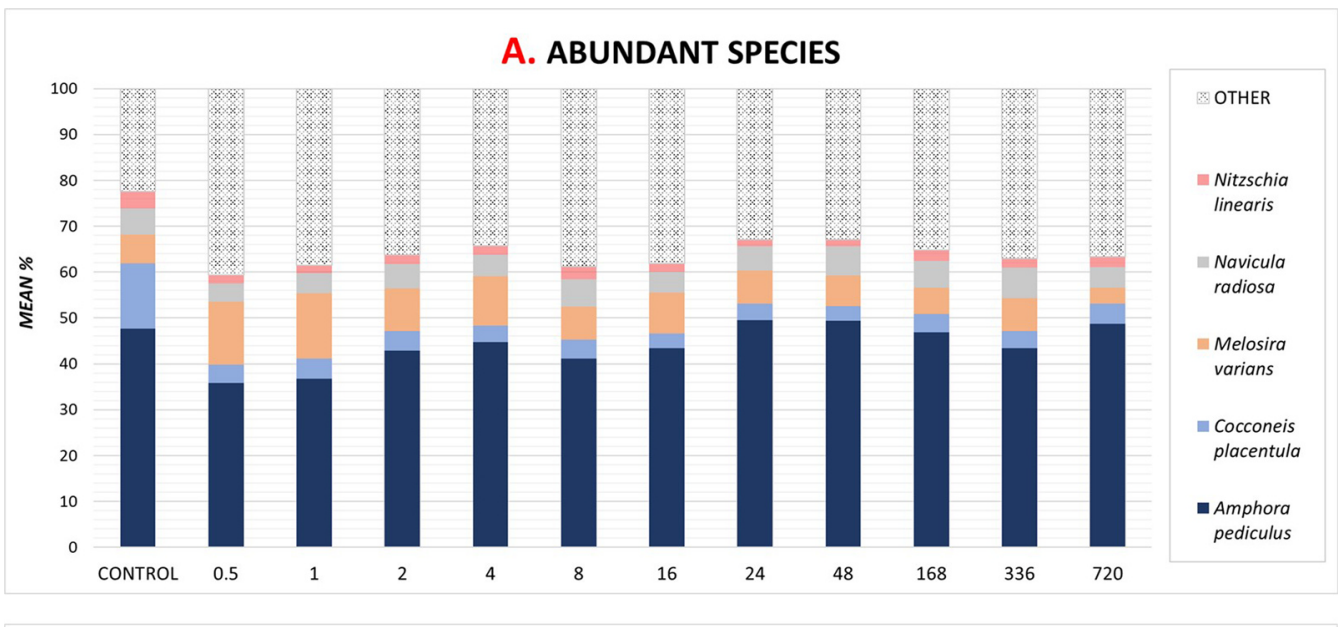

\section{B. LESS COMMON SPECIES}

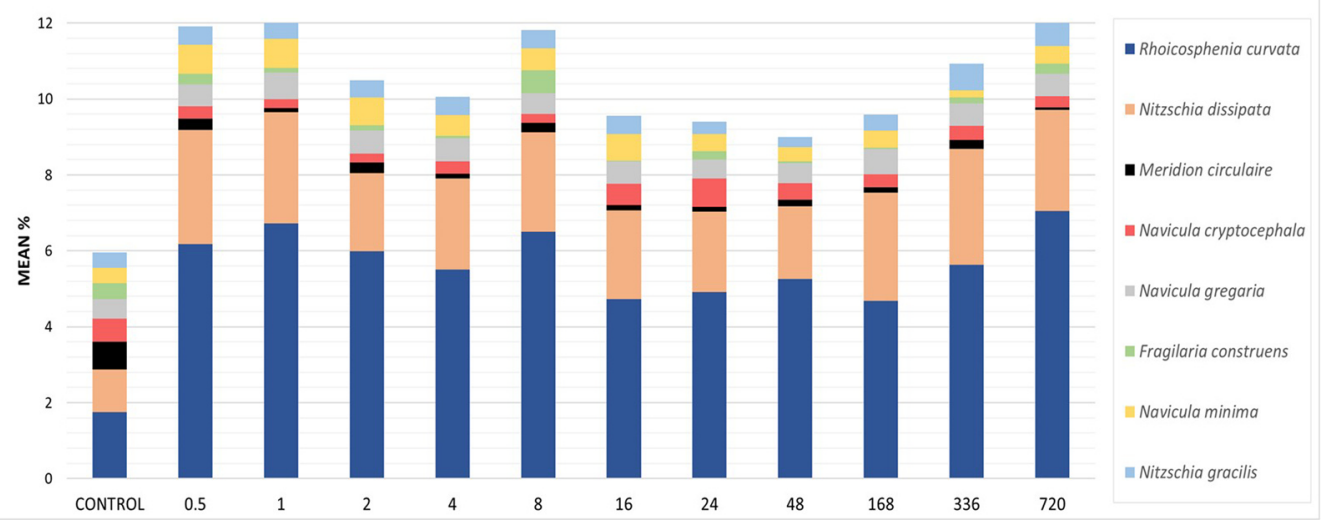

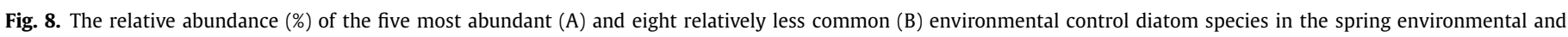
persistence samples. Overall values (per time since wear interval) are presented $(n=9)$, with trends for each clothing type included in Supplementary Figs. 8 and 9.

The species assemblage retrieved from the nylon persistence samples in the winter was extensively different to cotton and acrylic, prompting a separate analysis (Supplementary Fig. 5). Although all nylon spring samples were relatively comparable to the corresponding control, only the $0.5-2 \mathrm{~h}$ winter assemblages demonstrated similarity to the transfer site. The nylon samples retrieved beyond $8 \mathrm{~h}$ of wear in the winter were more likely to be excluded from the control assemblage based on the dynamics of species including Rhoicosphenia curvata and Cymatopleura elliptica.

The winter environmental sample was more species-rich (61 sp.) than the spring control. Despite this, consistently fewer taxa (0-41 sp.) from the transfer site were retrieved from the persistence samples in winter (Fig. 7a). Species were lost more rapidly from cotton and nylon, with acrylic again retaining a more species-rich assemblage over time. No diatom species were consistently retained on all clothing persistence samples in the winter (Fig. 7b). Several taxa were identified from 0.5 to $720 \mathrm{~h}$ of wear in acrylic, including Melosira varians which was also the only species retained in the winter cotton samples. None of the environmental taxa were a consistent indicator of contact between nylon and the transfer site following wear in winter.

Most of the seasonal persistence samples species assemblage also comprised taxa which were not identified in the corresponding environmental samples. Species including Amphora veneta, Gomphonema augur, Nitzschia amphibia, and Luticola mutica were frequently present in trace quantities $(<1 \%)$ of a persistent spring assemblage. Fewer secondary taxa were identified in the winter clothing samples and beyond $8 \mathrm{~h}$ of wear in both seasonal datasets (Supplementary Figs. 6, 7).

\subsubsection{Retention of abundant and less common taxa}

The five most abundant environmental diatom species were retained over the $720 \mathrm{~h}$ of wear in both seasons, although the relative abundance of those taxa in each persistence assemblage was more consistent and comparable to the control in spring (Figs. 8a, 9a). Amphora pediculus, Cocconeis placentula, Melosira varians, Navicula radiosa, and Nitzschia linearis accounted for 78\% (spring) and 63\% (winter) of each environmental assemblage, although their distribution in the overall persistence assemblage was lower (59-67\% [spring]; 36-63\% [winter]). A. pediculus was the most abundantly retained taxa in the spring (36-50\%) despite variability amongst the different clothing substrates (Supplementary Fig. 8). A. pediculus was consistently less abundant across the winter study (Fig. 9a). C. placentula and M. varians were identified in all persistence samples, although the relative abundance of $M$. varians in a retained assemblage was often greater than in the corresponding environmental sample. Although N. linearis and N. radiosa accounted for 3-4\% of the environmental and overall persistence assemblage in both sample runs, they were often missing from all winter cotton and nylon samples and beyond $24 \mathrm{~h}$ in those and denim substrates in the spring (Supplementary Fig. 8).

Several additional taxa including Rhoicosphenia curvata, Nitzschia dissipata, Fragilaria construens, Meridion circulare, Navicula gregaria and Navicula cryptocephala were frequently present in lower abundances $(<2 \%)$ of an environmental and clothing persistence assemblage (Figs. 8b, 9b) [Supplementary Data]. The retention of these less common species was variable between clothing substrate, persistence interval, and season. For example, although $R$. curvata and $N$. dissipata were consistently identified in all spring/winter samples, $N$. 


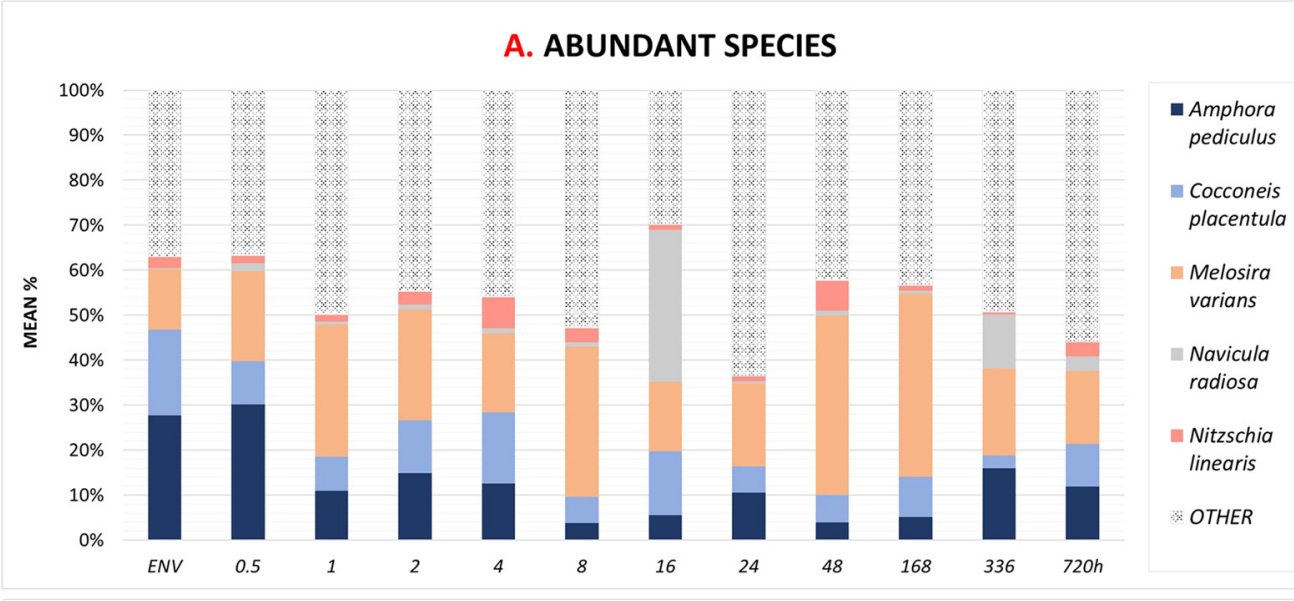

\section{B. LESS COMMON SPECIES}

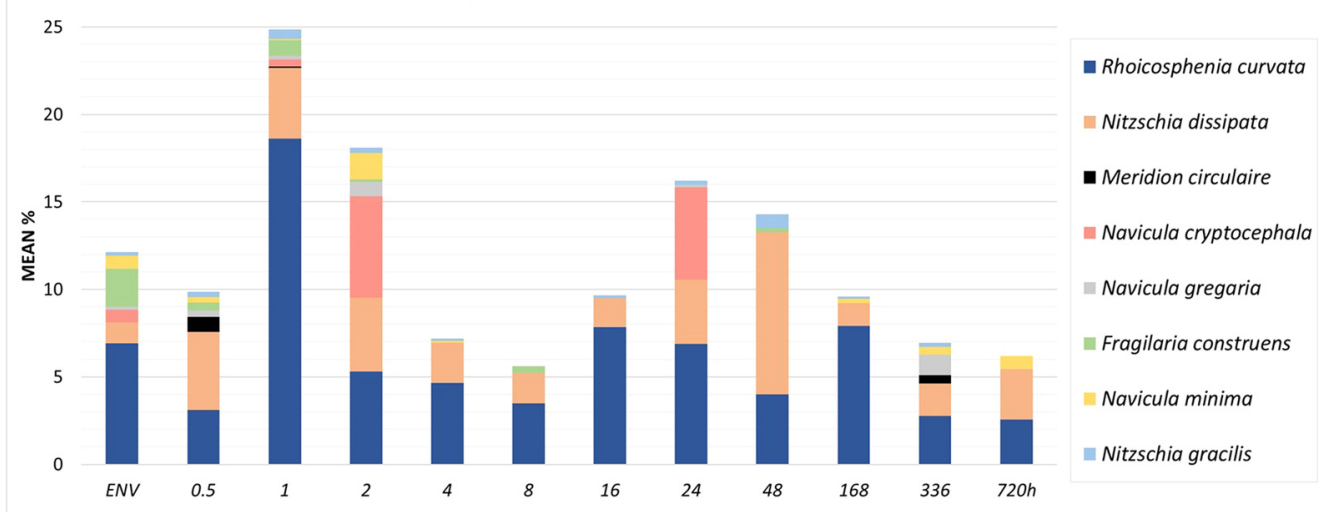

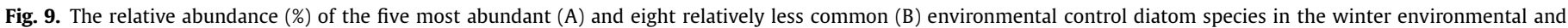
persistence samples. Overall values (per time since wear interval) are presented $(n=9)$.

gregaria was frequently absent from a retained nylon, linen, denim, and lycra diatom assemblage (Supplementary Fig. 9). Additional less common species including $N$. gracilis, N. minima, and F. construens were consistently identified in the spring persistence samples but were often missing beyond $2 \mathrm{~h}$ of wear in the winter (Figs. 8b, 9b).

\section{Discussion}

The results highlight that although diatom retention based on shape was relatively consistent over time, smaller diatoms $(<10 \mu \mathrm{m})$ persist on clothing in significantly greater abundance than larger valves. The persistent diatom assemblage was relatively stable over the one month of wear in spring, although significant differences were identified between clothing substrate due to diatom retention on nylon. Diatom persistence was more variable in the winter, with a lower species-richness and a more diverse assemblage identified in comparison to the environmental controls and the spring study. Several, and often the most abundant, environmental diatom taxa were consistently retained on clothing, providing useful markers for forensic comparisons with the site of initial transfer. The persistence of less common environmental taxa was less consistent over time and additional species (not identified in the environmental controls) were often identified within the spring and winter persistence samples. Importantly, these secondary species did not preclude associations between environmental and forensic samples (Figs. 4, 6). The data generated highlights the complexity of reconstructing diatom trace dynamics following wear over investigative timescales.

\subsection{Impact of diatom morphology on retention}

\subsubsection{Shape}

No statistically significant differences, or interactions, were identified when comparing the retention dynamics of centric, raphid, and araphid diatoms in the spring and winter (Supplementary Figs. 1, 2). Exploration of diatom retention based on shape does offer an insight into the variable overall persistence trends reported in [7]. For example, diatom loss from several clothing substrates previously reported intermediate variability $(2-24 \mathrm{~h})$ rather than a consistent loss of particulates over time. The findings here indicate that this variability is driven by different taxa depending on clothing type centric (nylon, denim), raphid (acrylic, denim, viscose, PVC), and araphid pennates (viscose, lycra, nylon). No general trends on centric or pennate diatom retention based on substrate characteristics (e.g. texture, weave structure) can be determined, reflecting similar variability in reconstructing diatom transfer [15] and overall persistence dynamics [7]. The retention (\%) of centric, raphid, and araphid pennate diatoms was seasonally consistent, indicating that variability in the extent of an initial transfer or a persistent assemblage, does not significantly affect the temporal dynamics of diatoms based on their shape.

Although not significant, the results indicate a complex relationship between valve shape, clothing substrate, and seasonal variability on diatom retention. Similar findings are reported in forensic palynology, where pollen retention on clothing varied between grains of different size, shape, and surface ornamentation [6]. As with pollen, diatoms initially grouped by shape are not uniform in 
their individual features, patterns, and micro-structures [21], which may contribute to some of the complexities identified with clothing substrates. Species-specific empirical testing of diatom persistence was subsequently necessitated from these initial findings; a recommendation also raised within previous pollen and diatom research $[6,15,16]$.

An initial assessment of the spatio-temporal dynamics of pennate and centric diatoms still offers a useful approach to assist with forensic reconstructions, particularly when an initial transfer site is unknown or full species identification is not feasible [17,22]. The distribution and abundance of diatoms within the environment is highly variable; the subsequent presence of different diatom morphologies within a forensic assemblage may therefore offer useful circumstantial information to indicate the nature of an initial transfer. For example, freshwater centric diatoms are frequently identified in the plankton (open water) and are more abundant in lotic (flowing) environments, whilst pennate taxa are typically bottom-dwelling and relatively ubiquitous in their distribution $[23,24]$.

\subsubsection{Size}

Smaller diatoms $(<10 \mu \mathrm{m})$ were retained in significantly greater abundance than larger diatoms in both sample seasons, with a relatively consistent decay curve identified in the loss dynamics of each group over time (Figs. 2, 3). The increased loss of larger diatoms following wear may have important implications for forensic sample comparison over time. Previous research identified that a transferred spring assemblage is predominantly comprised of larger $(>10 \mu \mathrm{m})$ diatoms (70-90\%) [15]. The accelerated loss of these diatoms, as demonstrated in this study, may result in the lack of several environmental species in a forensic sample recovered over time. As such, the transfer and persistence dynamics of diatoms based on their morphological traits should be considered during the exclusionary interpretation of diatom trace evidence samples [8,28].

In the spring study, a significant difference in diatom retention by size was identified amongst the nine clothing materials, suggesting that substrate characteristics may support or limit the ability of different sized diatoms to remain embedded over time. Initial differences in diatom transfer [15] and overall persistence [7] have been identified between clothing materials with similar surface characteristics. Variability attributed to diatom size in this study was driven by lycra and viscose (Fig. 2e, i). Both surfaces, compared to one another, are constructed of different weave structures and textures [15], indicating that retention dynamics based on diatom size cannot be inferred based on general recipient surface characteristics.

Seasonality impacted the persistence of diatoms based on size and significantly interacted with clothing type. For example, smaller diatoms were often absent from nylon beyond $8 \mathrm{~h}$ of wear in the winter (Fig. 3b). This variability may be attributed to a lower initial abundance and species-richness of diatoms (Supplementary Table 1a), as well as the ambient conditions in the winter. Interestingly, the retention dynamics of diatoms based on shape did not vary seasonally, indicating that environmental conditions are more likely to influence the loss of diatoms based on valve size from a forensic sample.

Size-selective trace evidence persistence has previously been demonstrated in glass [25], fibre [26], and soil [27] forensic studies, although a linear relationship was not identified between pollen size and retention on clothing [9]. The results from this study correspond with those relating to diatom persistence on footwear, where larger diatoms (in this case $>200 \mu \mathrm{m}$ ) were lost more readily than smaller valves over one week [16]. Here, the findings highlight that even smaller taxa $(<10 \mu \mathrm{m})$ are retained in greater abundance up to one month, although larger diatoms are still retrievable over extended timeframes.
The persistence of diatoms in both size fractions has important forensic implications. Several environmentally abundant taxa (including Amphora pediculus) were $<10 \mu \mathrm{m}$ in size and were successfully retained on clothing in similar concentrations to the control sample (Figs. 8, 9). A greater diversity of diatom species were identified as $>10 \mu \mathrm{m}$ in size. The sustained, albeit less abundant, presence of larger diatoms after each persistence interval may have been attributed to the selective loss of some taxa rather than the dynamics of the whole assemblage (Figs. 5, 7).

\subsection{Whole species assemblage dynamics over time}

The retained diatom assemblage was successfully compared to the source environment following one month of wear in the spring, despite a loss in species-richness over time (Supplementary Fig. 3; Supplementary Table 1a). This highlights the potential for diatoms to link clothing evidence with the site of initial transfer even when extensive periods of time have elapsed since contact. The importance of collecting representative environmental sample(s) from a known or proposed freshwater crime scene is also emphasised, even if a perpetrator and/or evidential exhibit has not yet been identified or retrieved [29]. This study involved the comparison of all persistence samples with only the site of initial immersion (albeit at different times of year); additional research may also seek to compare additional freshwater sites to determine whether a retained assemblage is consistent, remains site-specific, and whether diatom loss over time impedes reliable environmental discriminations.

A statistically significant difference was identified in the whole diatom assemblage recovered from the nine clothing substrates in spring (Fig. 4). This was driven by nylon, which consistently reported a lower species-richness and retained fewer species identified within the transfer environment (Fig. 5a, Supplementary Table 1b). Up to 22 of the environmental taxa were consistently retrieved from the other eight clothing samples whilst only Amphora pediculus, Navicula radiosa, and Rhoicosphenia curvata were routinely identified in a persistent nylon assemblage (Fig. 5b). Although the retention of those three taxa is useful in establishing the broad environment in which nylon was immersed, the lack of additional discriminatory (and often less common) taxa within an assemblage may limit the potential for robust and reliable forensic exclusions [15,20,28].

Variability in species retention on nylon corresponds with initial trends pertaining to diatom transfer and overall persistence. Fewer species were found to transfer to nylon in [15], with the transferred assemblage less comparable to the corresponding environmental controls than the other materials studied. The study of quantitative diatom persistence trends in [7] also identified that fewer diatoms with a highly variable overall retention rate were retained on nylon over one month of wear. The results from this and previous studies highlight that nylon is a less useful repository of diatom trace evidence, perhaps due to substrate characteristics (smooth, closed weave) limiting the entrainment and adhesion of an abundant and species-rich assemblage, as with leather in [16]. It is therefore recommended that other clothing items are selected for diatom recovery in forensic casework where possible. If unavailable, nylon clothing may still yield diatoms, although their forensic value should carefully be considered within the context of the empirical evidence bases developed here and in $[7,15]$.

The similarity of a persistent assemblage with an environmental control sample was more variable in the winter (Fig. 6; Supplementary Figs. 4, 5). Although the species assemblage retained on acrylic was relatively comparable to the winter environmental control, cotton and nylon were often highly variable due to seasonal differences in abundance [7] and species-richness (Supplementary Table 1b). Furthermore, only Melosira varians was routinely identified from 0 to $720 \mathrm{~h}$ of wear on cotton and no taxa were consistently identified throughout the nylon samples (Fig. 7b). These findings 
correspond with the seasonal diversity identified in previous diatom transfer and persistence research $[7,15]$ and highlight that exclusionary interpretations should consider that, although contact with a particular freshwater environment did occur, some diatom taxa may be scarce or absent from a forensic assemblage. The lack of diatoms retrieved from cotton and nylon clothing in the winter could be attributed to a relatively low transfer [15] or the increased loss of an assemblage following wear over time [7] (Fig. 7a).

\subsection{Retention of environmentally abundant and less common taxa}

The most abundant environmental species were consistently retrieved from the persistence samples, although some variability was identified between clothing type and sample season (Figs. 8a, 9a; Supplementary Fig. 8). The relative abundance of the most common taxa was often different in the forensic clothing samples when compared to the environmental control. For example, Melosira varians was often reported in a greater concentration of the persistence samples assemblage, reflecting initial diatom transfer trends [15]. Conversely, Nitzschia linearis and Cocconeis placentula were often missing from cotton, nylon, and polyester beyond $24 \mathrm{~h}$ of wear. This suggests that species-specific micro-textures, as well as valve morphology, also influence the retention or loss of diatoms from different clothing substrates over time.

Although the most abundant diatom species in a forensic sample yield useful intelligence for environmental comparison and exclusion, the presence of relatively less common taxa offers additional discriminatory value $[28,30]$. Several such taxa were consistently present as $1-5 \%$ of all seasonal persistence samples (Figs. $5 b, 8 b$ ), demonstrating that a retained diatom assemblage continues to incorporate less common indicators of the transfer site to assist with sample comparison following brief and extended periods of wear. Other species including Navicula minima (up to $4 \mathrm{~h}$ ) and Navicula gregaria (cotton, linen, acrylic) were identified in only a limited number of samples and may subsequently yield a less reliable indicator of the transfer site when time has lapsed during an investigation.

Both the most prevalent and relatively less common species were frequently absent from the assemblage of the winter persistence samples (Fig. 9). This reflects previous diatom transfer research findings [15] and suggests that a forensic sample retrieved hours or weeks post-transfer in the winter may not yield a representative diatom assemblage for comparison. Subsequently, seasonal variability in the extent [7] and species-richness of an evidential diatom assemblage should be considered during forensic interpretations.

\subsection{Inclusion of secondary species}

Finally, although most species identified in the persistence samples originated from the site of initial contact, additional taxa were also present within most of the clothing samples $(<1 \%$ of whole assemblage) (Supplementary Figs. 6, 7). Importantly, this inclusion did not preclude associations between the environmental and forensic persistence samples species assemblage (Figs. 4, 6). It is possible that such species were present, but not identified, in the three environmental control replicates prepared and analysed in each season; or that they were introduced to the persistence samples following exposure to secondary environments post-transfer. Such indirect background transfers have previously been identified in relation to pollen [31,32], fibres [33], gunshot residues [34], glass [35], and individual microbiomes [36], although they have not been directly explored in the context of freshwater diatoms. The findings presented here and in [7], and the aerial transportation of diatoms [37], recommends further study to investigate the prevalence of diatoms on clothing items which have not been in direct contact with proposed freshwater environments.

\section{Conclusion}

This study offers the first insight into diatom species dynamics following their persistence on clothing up to and including one month of wear. The results build on those presented in [7], and highlight that although the extent of diatom persistence is affected by clothing substrate, environmental seasonality, and diatom valve size; time since wear does not generally inhibit the comparison and exclusion of a retained assemblage with the site of initial contact following an initially abundant and species-rich transfer. Although the assessment of broad diatom characteristics (e.g. valve shape and size) offers a useful measure to understand diatom persistence, species-specific empirical testing is required to generate data that can reliably be used during the exclusionary interpretation of diatom trace evidence immediately post-transfer $[15,28]$ and when periods of time have lapsed in forensic casework [7].

The relative stability of a persistent diatom assemblage over time offers forensic potential for the comparison and exclusion of environmental and forensic samples, even when days and weeks have passed since a proposed transfer. The retention of environmentally abundant and various relatively less common diatom taxa in most of the clothing samples, indicates that diatoms may yield a useful discriminatory indicator over investigative timescales. More variability was identified in nylon and during the winter study, corresponding with a lower abundance and species-richness of diatoms following initial transfer [15]. It is therefore recommended that the value of a diatom trace evidence assemblage in casework is interpreted with reference to the empirical evidence bases developed through research exploring the spatial and temporal dynamics of diatoms exposed to forensically pertinent conditions.

Finally, the extensive diversity of diatom species and communities (as with other bioenvironmental trace indicators), compels additional forensic analyses than are typically required of more physically homogenous forms of trace evidence including glass, hairs, and fibres [20]. Subsequently, species assemblage changes should be assessed and incorporated during studies on diatom trace dynamics to determine how much evidence is retained and how comparable that evidence is to the site of initial transfer over time. Additional field-based simulations (rather than laboratory conditioned studies) of diatom transfer and persistence are strongly recommended to advance the initial empirical evidence bases developed here and in $[7,13,15,16]$, and to more closely replicate the circumstances likely to be encountered in forensic casework.

\section{CRediT authorship contribution statement}

K.R. Scott: Conceptualization, Methodology, Formal analysis, Investigation, Writing - original draft, Writing - review \& editing, Visualization. V.J. Jones: Conceptualization, Methodology, Writing review \& editing, Supervision. N.G. Cameron: Conceptualization, Methodology, Writing - review \& editing, Supervision. J.M. Young: Methodology, Software, Formal analysis, Writing - review \& editing. R.M. Morgan: Conceptualization, Methodology, Writing - review \& editing, Supervision.

\section{Conflict of interest}

The authors declare no competing information or conflicts of interest.

\section{Acknowledgements}

This research was funded by the Engineering and Physical Sciences Research Council of the UK through the Security Science Doctoral Research Training Centre (UCL SECReT) based at University 
College London (EP/G037264/1). The authors are grateful for technical support provided by the UCL Departments of Geography and Earth Sciences.

\section{Appendix A. Supporting information}

Supplementary data associated with this article can be found in the online version at doi:10.1016/j.forsciint.2021.110897.

\section{References}

[1] P.E. Wiltshire, Forensic ecology, botany, and palynology: some aspects of their role in criminal investigation, Criminal and Environmental Soil Forensics, Springer, Dordrecht, 2009, pp. 129-149.

[2] A. Prod'Hom, D. Werner, L. Lepot, G. Massonnet, Fibre persistence on static textiles under outdoor conditions, Forensic Sci. Int. 318 (2021) 110593.

[3] G. Cooper, The indirect transfer of glass fragments to a jacket and their subsequent persistence, Sci. Justice 53 (2) (2013) 166-170.

[4] M. Maitre, M. Horder, K.P. Kirkbride, A.L. Gassner, C. Weyermann, C. Roux, A. Beavis, A forensic investigation on the persistence of organic gunshot residues, Forensic Sci. Int. 292 (2018) 1-10.

[5] R.M. Morgan, K.R. Scott, J. Ainley, P.A. Bull, Journey history reconstruction from the soils and sediments on footwear: an empirical approach, Sci. Justice 59 (3) (2019) 306-316.

[6] J.C. Webb, H.A. Brown, H. Toms, A.E. Goodenough, Differential retention of pollen grains on clothing and the effectiveness of laboratory retrieval methods in forensic settings, Forensic Sci. Int. 288 (2018) 36-45.

[7] K.R. Scott, V.J. Jones, N.G. Cameron, J.M. Young, R.M. Morgan, Freshwater diatom persistence on clothing I: a quantitative assessment of trace evidence dynamics over time, Forensic Sci. Int. https://www.sciencedirect.com/science/article/pii/ S0379073821002188 (doi: https://doi.org/10.1016/j.forsciint.2021.110898).

[8] R.M. Morgan, J.C. French, G.E. Meakin, Understanding forensic trace evidence, Routledge Handbook of Crime Science, (2018) 393-407.

[9] P.A. Bull, R.M. Morgan, A. Sagovsky, G.A.J. Hughes, The transfer and persistence of trace particulates: experimental studies using clothing fabrics, Sci. Justice 46 (3) (2006) 185-195.

[10] J.M. Young, A. Linacre, Massively parallel sequencing is unlocking the potential of environmental trace evidence, Forensic Sci. Int. Genet. 50 (2021) 102393.

[11] Z.M. Burcham, H.R. Jordan, History, current, and future use of microorganisms as physical evidence, Forensic Microbiol. (2017) 25-55.

[12] N. Fucci, V.L. Pascali, C. Puccinelli, S. Marcheggiani, L. Mancini, D. Marchetti, Evaluation of two methods for the use of diatoms in drowning cases, Forensic Sci. Med. Pathol. 11 (4) (2015) 601-605.

[13] K.R. Scott, R.M. Morgan, V.J. Jones, N.G. Cameron, The transferability of diatoms to clothing and the methods appropriate for their collection and analysis in forensic geoscience, Forensic Sci. Int. 241 (2014) 127-137.

[14] V.J. Jones, Diatom introduction, in: S. Elias (Ed.), Encyclopaedia of Quaternary Science, Elsevier, Oxford, 2013, pp. 476-484.

[15] K.R. Scott, R.M. Morgan, N.G. Cameron, V.J. Jones, Freshwater diatom transfer to clothing: spatial and temporal influences on trace evidence in forensic reconstructions, Sci. Justice 59 (3) (2019) 292-305.

[16] E.A. Levin, R.M. Morgan, K.R. Scott, V.J. Jones, The transfer of diatoms from freshwater to footwear materials: an experimental study assessing transfer, persistence, and extraction methods for forensic reconstruction, Sci. Justice 57 (5) (2017) 349-360.

[17] A.J. Peabody, N.G. Cameron, Forensic science and diatoms, in: E.F. Stoermer J.P. Smol (Eds.), The Diatoms: Applications for the Environmental and Earth Sciences, Cambridge University Press, Cambridge, 2010.

[18] P.E. Wiltshire, Protocols for forensic palynology, Palynology 40 (1) (2016) 4-24.

[19] F.E. Round, R.M. Crawford, D.G. Mann, The Diatoms: Biology and Morphology of the Genera, Cambridge University Press, Cambridge, 1990.

[20] K.R. Scott, The Application of Freshwater Diatom Analysis in Forensic Geoscience: Establishing an Empirical Evidence Base for the Exclusionary Assessment of Trace Environmental Materials (Doctoral dissertation), UCL (University College London), 2017.

[21] R.W. Battarbee, V.J. Jones, R.J. Flower, N.G. Cameron, H. Bennion, L. Carvalho, S. Juggins, Diatoms, Tracking Environmental Change Using Lake Sediments, Springer, Dordrecht, 2002, pp. 155-202.

[22] N.G. Cameron, The Use of Diatom Analysis in Forensic Geoscience, 232(1) Geological Society, London, 2004, pp. 277-280 (Special Publications).

[23] H. Lange-Bertalot, G. Hofmann, M. Werum, M. Cantonati, Freshwater Benthic Diatoms of Central Europe: Over 800 Common Species used in Ecological Assessment, in: M.G. Kelly (Ed.), vol. 942, Koeltz Botanical Books, SchmittenOberreifenberg, 2017.

[24] H. Van Dam, A. Mertens, J. Sinkeldam, A coded checklist and ecological indicator values of freshwater diatoms from the Netherlands, Neth. J. Aquat. Ecol. 28 (1) (1994) 117-133.

[25] F. Brewster, J.W. Thorpe, G. Gettinby, B. Caddy, The retention of glass particles on woven fabrics, J. Forensic Sci. 30 (3) (1985) 798-805.

[26] C.N. Lowrie, G. Jackson, Recovery of transferred fibres, Forensic Sci. Int. 50 (1) (1991) 111-119.

[27] V. Chazottes, C. Brocard, B. Peyrot, Particle size analysis of soils under simulated scene of crime conditions: the interest of multivariate analyses, Forensic Sci. Int. 140 (2-3) (2004) 159-166.

[28] R.M. Morgan, P.A. Bull, The philosophy, nature and practice of forensic sediment analysis, Prog. Phys. Geogr. 31 (1) (2007) 43-58.

[29] E.J. Cox, Diatoms in forensic science, in: N. Marquez-Grant, J. Roberts (Eds.), Forensic Ecology Handbook: From Crime Scene to Court, Wiley, 2012, pp. 141-151 (In: Forensic botany).

[30] R.M. Morgan, P.A. Bull, Forensic geoscience and crime detection, Minerva Med. 127 (2007) 73-89.

[31] M.S. Zavada, S.M. McGraw, M.A. Miller, The role of clothing fabrics as passive pollen collectors in the north-eastern United States, Grana 46 (4) (2007) 285-291.

[32] J. Monckton-Smith, T. Adams, A.G. Hart, J. Webb, Introducing Forensic and Criminal Investigation, Sage, London, 2013.

[33] K.J. Sheridan, E. Saltupyte, R. Palmer, M.D. Gallidabino, A study on contactless airborne transfer of textile fibres between different garments in small compact semi-enclosed spaces, Forensic Sci. Int. 315 (2020) 110432.

[34] J. French, R. Morgan, An experimental investigation of the indirect transfer and deposition of gunshot residue: further studies carried out with SEM-EDX analysis, Forensic Sci. Int. 247 (2015) 14-17.

[35] J. McQuillan, K. Edgar, A survey of the distribution of glass on clothing, J. Forensic Sci. Soc. 32 (4) (1992) 333-348.

[36] A. Neckovic, R.A. van Oorschot, B. Szkuta, A. Durdle, Investigation of direct and indirect transfer of microbiomes between individuals, Forensic Sci. Int. Genet. 45 (2020) 102212.

[37] M.A. Harper, Diatoms as markers of atmospheric transport, The Diatoms Applications for the Environmental and Earth Sciences, (2001) 429. 